\title{
Epidemiology of Open Limb Fractures in a Country with Low-Income
}

\section{Noufanangue Kanfitine Kombate', Atchi Walla², Kolima Akloa², Komi Amakoutou2, Batarabadja Bakriga², Gamal Ayouba², Yaovi Yannick Dellanh'2, Anani Abalo², Assang Michel Dossim²}

${ }^{1}$ Department of Orthopaedic and Traumatology Surgery, Saint-Jean de Dieu d'Afagnan Hospital, Lomé, Togo

${ }^{2}$ Department of Orthopaedic and Traumatology Surgery, Sylvanus Olympio Teaching Hospital, University of Lomé, Lomé, Togo

Email: kludovick67@yahoo.fr

How to cite this paper: Kombate, N.K., Walla, A., Akloa, K., Amakoutou, K., Bakriga, B., Ayouba, G., Dellanh, Y.Y., Abalo, A. and Dossim, A.M. (2017) Epidemiology of Open Limb Fractures in a Country with Low-Income. Open Journal of Orthopedics, 7, 356-361.

https://doi.org/10.4236/ojo.2017.711036

Received: September 26, 2017

Accepted: November 6, 2017

Published: November 9, 2017

Copyright $\odot 2017$ by authors and Scientific Research Publishing Inc. This work is licensed under the Creative Commons Attribution International License (CC BY 4.0).

http://creativecommons.org/licenses/by/4.0/

\begin{abstract}
Introduction: Open limb fractures are frequent and severe. Very often they result from high velocity traffic accidents. The aim of this study was to identify the epidemiologic aspects of open limb fractures in order to improve prevention and care. Material and Methods: It was a retrospective study carried out in the Department of Orthopaedic and traumatology Surgery of Afagnan hospital. It concerned the files of patients admitted from January $1^{\text {st }}$ to December $31^{\text {st }}$ 2016. Patients of 15 years old and older who presented open limb fractures were included in the study. The study variables were: age, sex, occupation, trauma aetiology, injury mechanism, location and type of lesions. An X-ray (antero-posterior and lateral view) of the injured limb segment was done in all patients. Results: On 87 patients, 148 cases of fractures were collected. The mean age was 38.08 years with extremes of 15 and 82 . There were 23 women $(26.4 \%)$ and 64 men $(73.6 \%)$. The most common etiology was traffic accidents (73.5\%). Motorcycle accidents (58.3\%); accidents involving motorcycle and car (19.4\%). Accidents at work represented (16.1\%). Lower limbs were more affected (77.1\%). Open fractures classified Gustillo-Anderson type III were predominant with type IIIa (51.0\%), IIIb (32.6\%) and IIIc (16.3\%). Conclusion: Open limb fractures are severe. They are mainly due to the increase of high-velocity traffic accidents. This explains the predominance of the young male population. Road safety and all actors' behaviour change are essential for the reduction of traffic accident morbidity.
\end{abstract}

\section{Keywords}

Open Fracture, Limb, Epidemiology 


\section{Introduction}

The open fractures of the extremities are very frequent, remain a real challenge for the surgeons and cause a significant morbidity [1]. They are caused for more the share of time by the accidents of interstate at the time of the high-energy traumas. The latter are in constant increase, because of increase in the car fleet and the proliferation of the machines at very high speeds. They engage sometimes the vital prognosis of traumatized and when they are not deadly, they involve heavy impairments which often pose problems of socio-professional reintegration of the patients thus constituting true public health problems [2] [3] [4]. Apart from the fracture, the skin lesions muscles, vascular nervous and sinewy are frequently associated making complex the treatment [3]. This treatment must be codified well starting on the place of the accident and integrating a multidisciplinary team [5], namely: the emergency medical treatment which is generally put at contribution in the first hours, the physical therapy and of readjustment which deals with the physical therapy in order to limit the squealers, the general medicine which ensures the long-term follow-up and also the occupational medicine because most of the road accidents are commuting accidents (residence-work). In the developing countries like ours, the shortage of facility and financial means complicates the treatment of the open fractures of extremities. We had conducted this study in order to release the epidemiological profile, to adapt the treatment of these injuries and to formulate suggestions for an accident prevention.

\section{Material and Method}

This study was conducted in the Department of Orthopaedic and Traumatology surgery hospital of Afagnan which was a tertiary care institute in Togo. It was about a retrospective study which enrolled the records of the patients of more than 15 years, having presented an open fracture of extremity during the period of time of January first to December 31 $1^{\text {st }}$, 2016. This hospital receives 2482 patients by year including 482 closed fractures and 148 open fractures. All the patients profited from a radiographic evaluation and the treatment of the lesion observed. The incomplete records and the records of the patients presenting the traumas other than the extremities were not included in our study. Information collected enabled us to analyse the age, the sex, the occupation, the source, the etiology of the trauma, the injury mechanism, the seat of the lesions and the type of injury observe.

\section{Results}

87 patients were enrolled for this study and 148 fractures were observed. The mean age was 38.08 years $(15-82)$. We noted a predominance of the age bracket of 16 - 29 years (Figure 1 ).

They were 23 women (26.4\%) and 64 men (73.6\%). The sex ratio was 2.7. The most found etiology was the accidents of the public highway (73.6\%), the industrial 
accidents represented (16.1\%) (Figure 2).

We found: fifty and one case of accident motorbike-motorbike (58.3\%); 17 cases of automobile- Motorbike accident (19.4\%), 9 cases of accident motorbikepedestrian (Table 1). According To the occupation, the patients having a liberal profession were touched in 70 cases $(80.4 \%)$. The lower extremity was touched the most with a frequency of $77.01 \%$ (Table 2).

The open fractures type III of Gustilo-Anderson were predominant (56.3\%): The type IIIa, standard IIIa and type IIIa accounted for $51.1 \%$ respectively; $32.6 \%$ and $16.3 \%$. The open fractures of type II accounted for $32.2 \%$. The lesions of the type I as for them accounted for only $11.5 \%$.

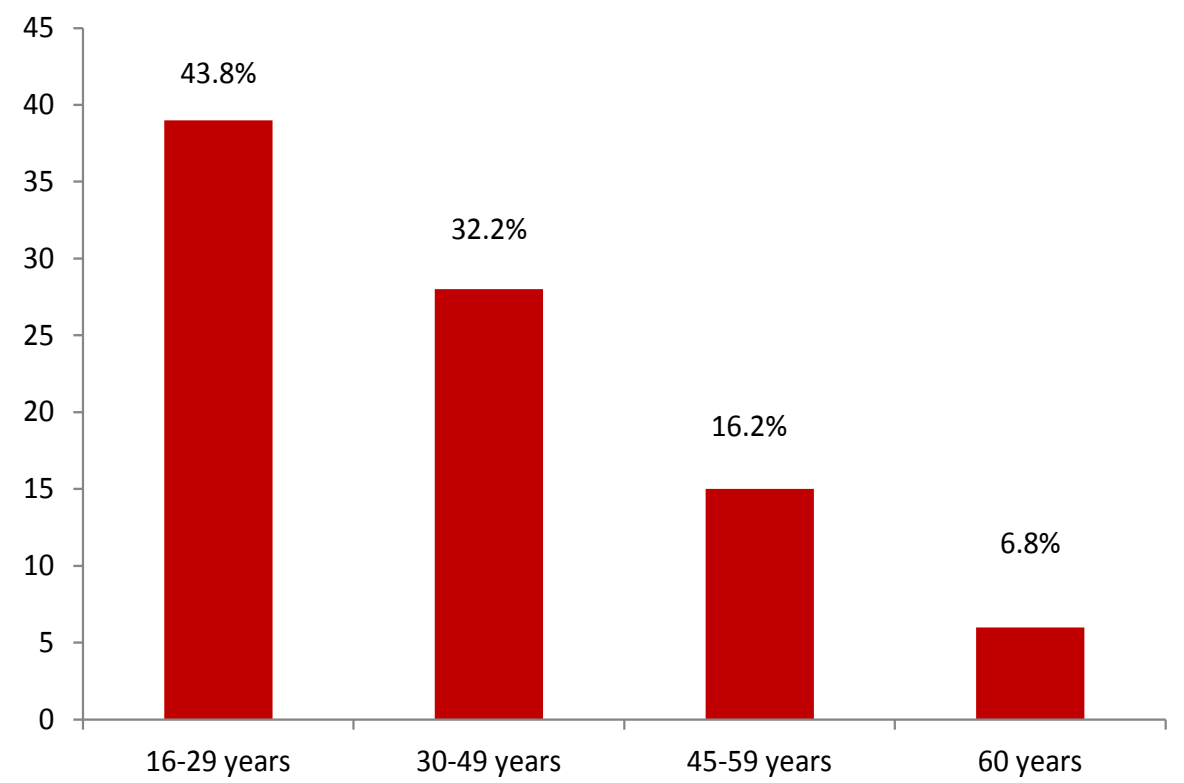

Figure 1. Distribution of the Fractures according to the Slice of Elderly.

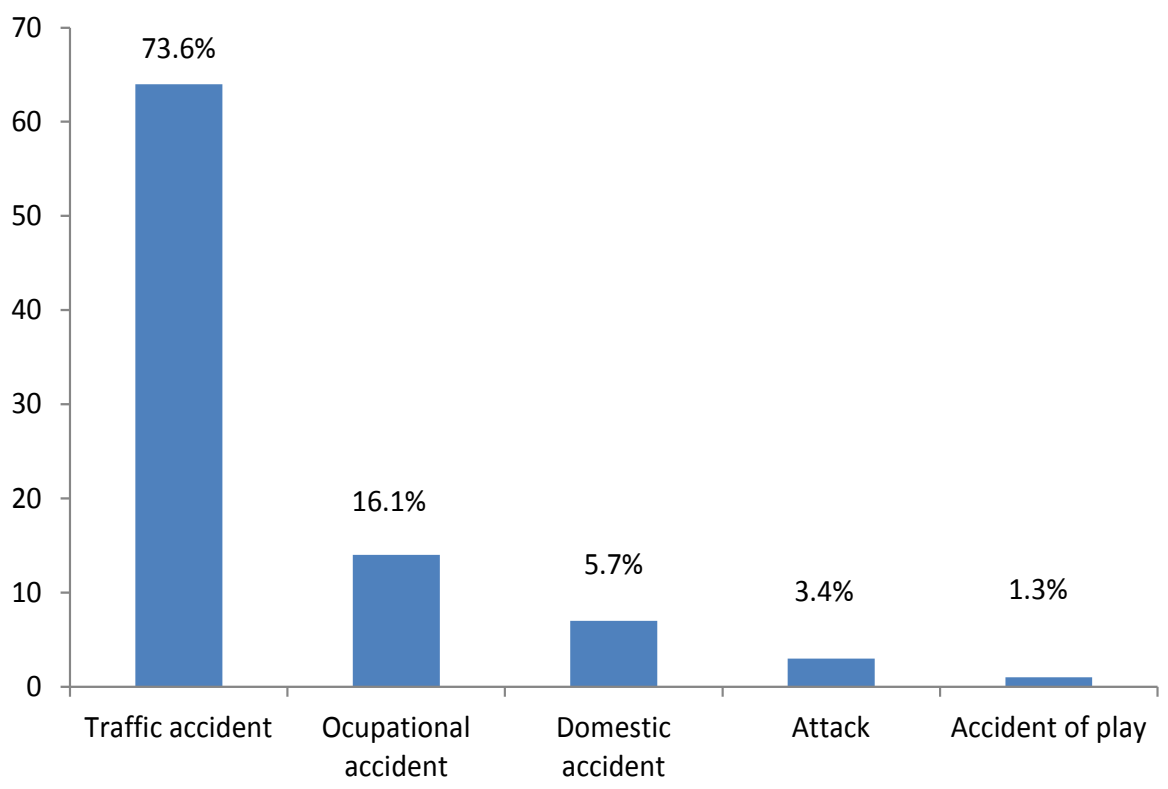

Figure 2. Distribution according to the etiology of the open Fractures. 
Table 1. Distribution according to the type of accidents.

\begin{tabular}{ccc}
\hline Types of accident & Number & Percentage (\%) \\
\hline motorbike-motorbike Accident & 51 & 58.3 \\
Automobile Accident & 17 & 19.5 \\
Mobike-Piedestrian Accident & 9 & 11.1 \\
Auto- Piedestrian Accident & 6 & 06.5 \\
Cyclist Accident & 4 & 4.6 \\
TOTAL & 87 & 100 \\
\hline
\end{tabular}

Table 2. Distribution according to the seat of the lesions.

\begin{tabular}{ccc}
\hline Seat of Lesions & Number & Percentage \\
\hline Upper extremity & 34 & $22.9 \%$ \\
Shoulder & 4 & 2.7 \\
Upper arm & 6 & 4.0 \\
Elbow & 2 & 1.4 \\
Forearm & 12 & 8.1 \\
Wrist & 2 & 1.3 \\
Hand & 8 & 5.4 \\
Lower Extremity & 114 & 77.1 \\
Hip & 7 & 4.7 \\
Thigh & 9 & 6.2 \\
Knee & 10 & 6.7 \\
Leg & 58 & 39.2 \\
Ankle & 18 & 12.2 \\
Foot & 12 & 8.1 \\
TOTAL & 148 & 100 \\
\hline & &
\end{tabular}

\section{Discussion}

The purpose of our retrospective study was to describe the epidemiological aspects of the open fractures extremities. The limits of this work are related on the retrospective character of this study, and our sample was negligeagle compared to those of the literature. We enrolled 148 cases of open fracture among $87 \mathrm{pa}$ tients with a 38.08 years median age. The age bracket most concerned was that of 16 - 29 years. According to age pyramid, the young people are majority in our country. The predominance of this age bracket was also found by Samuel John and al. [2], Nirmal Raj et al. [6]. The topics of male sex were touched with a sex ratio of 2.7. This report was made by Chalya et al. [7], Twagirayezu et al. [8] and could be explained by the fact why these young people devote themselves to even hazardous occupations at the risk. They are followers of control with speeding, sometimes under the influence of alcohol and other drugs [9]. The patients having 
a liberal profession were mainly touched. Konan and al. also noted a predominance of this professional, very active and very mobile [3]. The accidents of the public highway were at the origin of the open fractures of extremity in $73.56 \%$ of the cases. For Frederico Carlos et al., [10] the open fractures were caused by the accidents of the public highway in $84 \%$ of the cases of which $57 \%$ implied the motorcyclists. The violence of the bumps at the time of these traumas could explain this raised frequency, especially when the patient is with motor bike and without any protection for the extremity. The lesions seat preferentially at the lower extremity $77.02 \%$ with a predominance with the leg (39.18\%). The lesions of the types III of Gustilo prevailed in our series. In the study reported by AM Ali et al., the lesions of the type IIIa, IIIb and IIIc accounted for $8 \%, 76 \%$ and $16 \%$ respectively [11]. With regard to the lesions of the type III, our results correspond to those of Frederico Carlos et al. [10] which also noted a predominance of type IIIa Lesions. The Types IIIa, IIIb and IIIc respectively accounted for $81 \%$, $12 \%$ and $7 \%$. Most of the lesions of the type III testify to the violence of the bump at the time of traumas and the Injury Severity which they generate.

\section{Conclusion}

The increase in road traumatology with high-energy is at the origin of the open fractures extremities generally serious. She explains the paramount place of the young topics of male sex which are followers of the high-risk hazardous activities. An absolute respect of the rules of traffic control and behavioural change of all the road users will make it possible to reduce the morbidity and the mortality of these lesions.

\section{References}

[1] Yarrow, J., Rahman, S., Marsden, N., Pallister, I. and Hemington-Gorse, S. (2015) Management of Open Lower Limb Injuries in South West England and Wales. Annals of the Royal College of Surgeons of England, 97, 35-39. https://doi.org/10.1308/003588414X14055925058472

[2] Clelland, S.J., Chauhan, P. and Mandari, F.N. (2016) The Epidemiology and Management of Tibia and Fibula Fractures at Kilimanjaro Christian Medical Centre (KCMC) in Northern Tanzania. Pan African Medical Journal, 25, 10-12.

[3] Konan, K.J., Assouan, K.T., Kouassi, F. and Ehua, S.F. (2006) Epidemiology of Traffic Road Injuries in Teaching University Hospital of Yopougon. International Medical Science Review, 8, 44-48.

[4] Court-Brown, C.M., Bugler, K.E., Clement, N.D., Duckworth, A.D. and McQueen, M.M. (2012) The Epidemiology of Open Fractures in Adults: A 15-Year Review. Injury, 43, 891-897. https://doi.org/10.1016/j.injury.2011.12.007

[5] Nanchahal, J., Nayagam, S., Khan, U., et al. (2009) Standards for the Management of Open Fractures of the Lower Limb. BAPRAS, London.

[6] Gopinathan, N.R., Santhanam, S.S., Saibaba, B. and Dhillon, M.S. (2017) Epidemiology of Lower Limb Musculoskeletal Trauma with Associated Vascular Injuries in a Tertiary Care Institute in India. Indian Journal of Orthopaedics, 51, 199-204.

[7] Chalya, P.L., Mabula, J.B., Dass, R.M., Mbelenge, N., Ngayomela, I.H., Chandika, 
A.B. and Gilyoma, J.M. (2012) Injury Characteristics and Outcome of Road Traffic Crash Victims at Bugando Medical Centre in Northwestern Tanzania. Journal of Trauma Management and Outcomes, 6, 1. https://doi.org/10.1186/1752-2897-6-1

[8] Twagirayezu, E., Teteli, R., Bonane, A. and Rugwizangoga, E. (2008) Road Traffic Injuries at Kigali University Central Teaching Hospital, Rwanda. East and Central African Journal of Surgery, 13, 73-76.

[9] Chalya, P.L., Mabula, J.B., Ngayomela, I.H., Kanumba, E.S., Chandika, A.B., Giiti, G., Mawala, B. and Balamuka, D. (2010) Motorcycle Injuries as an Emerging Public Health Problem in Mwanza City Tanzania: A Call for Urgent Intervention. Tanzania Journal of Health Research, 12, 214-221. https://doi.org/10.4314/thrb.v12i4.55500

[10] Frederico Carlos, J.N., Marina de Paula, C., Bernardo Aurelio, F.A., Pablício, M.F., Efferson, C.A. and Robson, A.S. (2016) Analysis of the Characteristics of Patients with Open Tibial Fractures of Gustilo and Anderson Type III. Revista Brasileira de Ortopedia (English Edition), 51, 143-149. https://doi.org/10.1016/j.rboe.2016.01.002

[11] Ali, A.M., McMaster, J.M., Noyes, D., Brent, A.J. and Cogswell, L.K. (2015) Experience of Managing Open Fractures of the Lower Limb at a Major Trauma Centre. Annals of The Royal College of Surgeons of England, 97, 287-290.

https://doi.org/10.1308/003588415X14181254789367 